DR. SKANDARUPAN JAYARATNAM (Orcid ID : 0000-0002-2730-7454)

DR. ALEXIS SHUB (Orcid ID : 0000-0001-9719-5753)

Article type : Original Manuscript

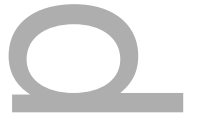

\title{
A prospective review of perinatal mortality at Hospital Nacional Guido Valadares (HNGV)
}

Short title: A prospective review of perinatal mortality at HNGV

\section{Word Count \\ Abstract: 241 \\ Main manuscript: 2481}

\section{Tables: 4}

Key words: Timor-Leste, stillbirth, pregnancy outcomes, fetal death, perinatal death.

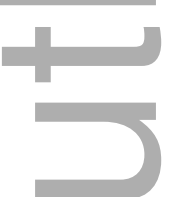

A prospective review of perinatal mortality at 'The National Hospital Guido Valadares' (HNGV)

Background: Timor-Leste has one of the highest perinatal mortality rates in the Asia-Pacific region. Consistent and accurate data collection improves understanding of perinatal outcomes and

This is the author manuscript accepted for publication and has undergone full peer review but has not been through the copyediting, typesetting, pagination and proofreading process, which may lead to differences between this version and the Version of Record. Please cite this article as doi: $\underline{10.1111 / \text { AJO.12991 }}$

This article is protected by copyright. All rights reserved 
facilitates the development of interventions to reduce stillbirths and early neonatal deaths.

\section{Aims:}

1) To identify changes in the rates of stillbirth and early neonatal deaths from previous published data

2) To determine if prospective data collection and the application of the simplified CODAC classification allows better identification of perinatal deaths in Timor-Leste.

Methods: A prospective audit of perinatal deaths of women delivering at HNGV was undertaken from January to June 2016 inclusive. Hospital birth registry, maternal and neonatal records were reviewed to determine the most likely aetiology and classification of perinatal deaths using the simplified Causes Of Death and Associated Conditions (CODAC) system.

Results: One hundred and ten stillbirths and twenty-eight early neonatal deaths were identified. Fifty- four percent of perinatal deaths occurred antepartum, 26\% intrapartum and 20\% were early neonatal deaths. Cause of death among stillbirths could not be ascertained in $40 \%$ of cases. Intrapartum asphyxia was the commonest identified aetiology of intrapartum and early neonatal deaths.

Conclusion: There has been limited improvement in the rate of stillbirths and early neonatal deaths at HNGV. Intrapartum hypoxia and maternal hypertensive conditions were the most common identified aetiologies highlighting areas where targeted interventions may help reduce high perinatal mortality rates. Aetiology of perinatal deaths, particularly antepartum stillbirths was difficult to discern even when well tested classification systems are used.

\section{Introduction:}

Globally around 2.6 million babies are stillborn every year and another 2.1 million live-born babies die before the end of the first week of life. ${ }^{1,2}$ The vast majority occur in low and middleincome countries (LMIC) ${ }^{3,4}$. Data on stillbirth and early neonatal mortality in Timor-Leste is limited. The Timor-Leste Demographic and Health Survey (TLDHS), a nationwide survey of selected households indicated a perinatal mortality rate (PNMR) of 20/1000 live births, a stillbirth rate of 3/1000 births and an early neonatal death rate of approximately 17/1000 live birth ${ }^{5}$. Published data from retrospective reviews at Hospital Nacional Guido Valadares (HNGV) indicated a stillbirth rate (SBR) of 29/1000 births ${ }^{6}$ and a neonatal mortality rate (NNMR) of 18/1000 live births respectively, without a specific assessment of early neonatal deaths ${ }^{7}$. In comparison, Timor Leste's closest neighbours, Indonesia and Australia have stillbirth rates of 13/1000 and 7/1000 births and neonatal mortality rates of $14 / 1000$ and $2 / 1000$ live births respectively ${ }^{8,9}$. 
Accurate classification of causes and associated conditions for perinatal deaths may inform strategies to reduce mortality rates. This is particularly so with classification in LMICs which present many challenges: a substantial proportion of home births, limited antenatal care, uncertain gestational age and a lack of laboratory investigations, including autopsy ${ }^{10,11}$.

Globally, many different systems are used for classifying perinatal deaths. These differ in the number of causes recorded, whether antepartum and intrapartum stillbirths are differentiated, whether stillbirths and neonatal deaths are included concurrently and whether International Classification of Disease (ICD) classification codes are utilised ${ }^{12}$. The ICD system is currently the only global system for classifying perinatal deaths but has not been adapted specifically to classify stillbirths, with limited codes for conditions specific to the perinatal period particularly placental pathologies ${ }^{12}$. Of the existing classification systems that have been tested in LMIC, the PSANZPDC and CODAC classification systems best supplement the ICD. ${ }^{12}, 13$ Simplification of the main classification categories (simplified CODAC classification system) may be necessary in settings where limited investigations or only verbal autopsy data are available. ${ }^{13}$ (Appendix 1).

We aimed to audit perinatal mortality at HNGV to determine if there has been a change in PNM since previous publication, to determine if prospective collection improved classification and to test the applicability of the Simplified CODAC Classification in Timor-Leste.

\section{Methodology: \\ Setting:}

HNGV is the main obstetric referral centre for Timor-Leste's population of 1.2 million and provides care for approximately 5000 women presenting each year from the local area and referred from other centres. ${ }^{14}$ Most antenatal care is undertaken outside the hospital system in Community Health Centres (CHCs) or Health Posts (HPs) - 77\% of pregnant women received at least 4 antenatal care visits with the percentage higher in urban areas $(87 \%)^{5}$.

The Neonatal Unit (NNU) admits approximately 1200 babies per year, around two thirds of whom are inborn. The unit is able to provide continuous positive airway pressure (CPAP) and oxygen, but neither invasive ventilation nor surfactant are available.

Births are recorded in the labour ward register: Mode of delivery, birth weight, gender, Apgar score, indication for caesarean section and estimated gestational age are recorded. Neonatal deaths are recorded in the NNU register.

\section{Inclusion Criteria and Definitions}

This prospective observational study included all perinatal deaths occurring at HNGV $1^{\text {st }}$ January 2016- 30 $0^{\text {th }}$ June 2016. 
Stillbirth was defined as death of a fetus weighing $\geq 500 \mathrm{~g}$ or, if birth weight was unavailable, gestational age of $\geq 22$ weeks. Early neonatal death was defined as death within 7 days of birth. Perinatal deaths were defined as a combination of stillbirths and early neonatal deaths (NNDs).

Perinatal mortality meetings have been held since 2013. All stillbirths and early NNDs occurring within the hospital, and some antepartum stillbirths diagnosed on arrival to the unit, were discussed at these monthly combined Obstetric/Neonatal Perinatal mortality meetings consisting of at least two paediatricians, two obstetricians, senior neonatal nursing and midwifery staff. The most likely cause of death of cases presented was determined at the meeting.

Cause of death of stillbirths not discussed at the meeting, were reviewed by two of the authors (BJ, SJ) outside the monthly meeting.

\section{Data collection and analysis}

Cases were identified and collected daily by the authors, through participation in unit meetings and regular visits to the labour, antenatal and postnatal wards and the NNU. Once identified, a structured data form was completed and entered into an Excel spreadsheet. Parameters included age, parity, gestational age, area of primary residence during the pregnancy, maternal haemoglobin $(\mathrm{Hb})$ and antenatal serology, antenatal obstetric complications, duration of labour, mode of delivery, delivery complications and birth weight. Examination of the fetus and placenta was undertaken for grossly abnormal features e.g. significant maceration, retroplacental clot and overt congenital abnormalities. Gestational assessment of the stillborn fetus was not undertaken.

The stillbirth (SB) rate (antepartum or intra-partum deaths per 1000 births) and the perinatal mortality rate (number of stillbirth and early neonatal deaths per 1000 births, PNMR) were calculated. Relative risk (RR) was calculated to explore the association between the risk of severe maternal outcomes according to age and parity. Parity was defined as the number of births over 20 weeks $(0$ to $\geq 5$ ) while maternal age was divided into 5-year age groups $(<20$ to $\geq 40$ years). Incidence rates of perinatal death were calculated for each subgroup. The lowest incidence rate was assigned as the index rate (1.0) and other risks were calculated relative to this value. Z-tests were conducted to test for significant differences between RR of perinatal deaths and age and parity.

Ethics approval was obtained from the Human Research Ethics Committee at Institute National Saude (INS) no:MS-INS/DE/I X/2016/1005.

\section{Results:}

There were 2525 births and 138 perinatal deaths during the study period: 110 were stillbirths (74 antepartum, 36 intrapartum) and 28 early NNDs, giving an institutional stillbirth rate of 44 per 1000 births, an early NND rate of 12 per 1000 live births and PNMR of 55 per 1000 births. 
Of the 138 perinatal deaths, 135 were from singleton pregnancies, one was a second twin who died three days after birth and another a twin pregnancy with two early NNDs.

Approximately $40 \%$ of the perinatal deaths occurred in women referred from outside the Dili Metropolitan area.

Eighty-two percent of women in the PND cohort had vaginal deliveries (78\% cephalic, 22\% breech), $15 \%$ underwent caesarean section and in 3\% the mode of delivery was unknown (Appendix 2). The overall rates of breech vaginal birth and caesarean section for the unit during this period were $2 \%$ and $21 \%$ respectively.

Univariate analysis examining the effect of age and parity is shown in Table 1. The risk of perinatal death was highest in the 25-29 year age group, 30-34 year age group and $\geq 40$ year age groups as well as in grand multiparous women.

The majority of perinatal deaths (44\%) occurred in babies weighing between $2500 \mathrm{~g}$ and 3999g. Twenty (17\%) of PNDs had a birthweight of $<1 \mathrm{~kg}$ and one weighed $\geq 4 \mathrm{~kg}$ (Appendix 2). The data for place of residence, multiple pregnancy and birth weight for the entire birth cohort was not available for comparison.

Among antepartum stillbirths, the most common classification was maternal hypertensive disease although nearly two thirds of cases were classified as 'unknown' (Table 2). Intrapartum stillbirths accounted for $32 \%$ of stillbirths with intrapartum asphyxia accounting for 14 (39\%) cases (Table 3). Simplified CODAC classification of early neonatal death (Table 4) resulted in 50\% of cases being classified as due to intrapartum asphyxia and $32 \%$ to extreme prematurity.

\section{Discussion:}

This is the first published study of prospectively reviewed perinatal deaths in Timor-Leste. Over the six month period of the study the stillbirth rate was 44/1000 births and perinatal mortality rate 55/1000 births. Using a gestational age cut-off of 28 weeks and an equivalent weight of $1 \mathrm{~kg}$ for international comparison, resulted in SB and PNM rates of 38/1000 births and 49/1000 births respectively. By comparison, national $\mathrm{SB}$ and $\mathrm{PNM}$ rates for loss at 28 or more weeks or $1 \mathrm{~kg}$ or higher birthweight were slightly lower in Papua New Guinea (SB rate of 28/1000 births, PNMR 30/1000 births), Indonesia (SB rate 13/1000, PNMR 21/1000) and significantly lower in Australia (SB rate 7/1000, PNMR 9.7/1000) ${ }^{8,9,15}$.

The high institutional stillbirth rate may in part be explained by the large number of antepartum stillbirths referred from community health centres, health posts and other hospitals throughout the country. Verification and induction for patients with suspected fetal demise are often unavailable at peripheral sites and therefore suspected cases of stillbirth are referred to the national hospital for further assessment and management. Wilkins et al., found a SB Rate of 29/1000 births in the only other published study of stillbirths in Timor - Leste, a retrospective audit of SB over a 12 month period ${ }^{6}$. Wilkins' study was conducted at the same institution but did not include early 
neonatal deaths, which are often associated with adverse intrapartum events. The lower rates identified in Wilkins' study may be reflective of its retrospective nature and the significant data collection limitations encountered. The $2015 \mathrm{HNGV}$ maternity unit report revealed 192 stillbirths for the year, more suggestive of the numbers attained in our study ${ }^{14}$. Our rate of early NND at HNGV was consistent with the TLDHS data though previous institutional data for comparison was unavailable. Although an increase in referrals or better identification of cases of stillbirth may have contributed to the increased numbers, this study nevertheless indicates limited improvement in perinatal outcomes at HNGV.

In our study, the relative risk of perinatal mortality was twice as high in women aged 25-29, 30-34 years and $\geq 40$ years compared to women aged 20-24 and three times higher in grand multiparous women as compared to women with a parity of 2. Similar to other LMIC countries, there is a significant unmet contraceptive need in TL, which may prevent delaying pregnancy, control of fertility, and ultimately contribute to maternal and perinatal deaths ${ }^{5,16}$. The higher rate of perinatal deaths with higher parity mirrors similar findings associated with severe maternal outcomes in Timor-Leste ${ }^{17}$ and may highlight areas such as improved education, provision and utilisation of contraception, where benefit may accrue.

Globally infections, congenital anomalies, placental abruptions, pregnancy induced hypertension and other placental insufficiencies cause most antepartum deaths $2,18,19$. The most commonly identified antepartum classification in our study was maternal hypertensive disorders and placental abruption. Contributions to perinatal deaths from infections such as HIV, syphilis or malaria was difficult to ascertain due to inconsistent antenatal testing for these infections in our cohort - less than $10 \%$ had some evidence of antenatal serological testing. HIV and malaria are rare in Timor-Leste 20,21 and unlikely to contribute to perinatal mortality but the burden of syphilis on perinatal deaths is unknown. The relative contribution of congenital abnormalities in our cohort was limited and may reflect an underdiagnoses from gross external examination without the presence of autopsy and other diagnostic assessments. Approximately $60 \%$ of the antenatal stillbirths in our study were of 'unknown' causes - associated adverse factors such as growth restriction and malpresentation were present in 13 cases, but it was unclear if they directly contributed to mortality.

Approximately $32 \%$ of stillbirths occurred intrapartum consistent with studies from other $\mathrm{LMIC}^{15,}$ 22, 23. Intrapartum asphyxia was the single most significant aetiology identified in intrapartum and early neonatal deaths in our study ${ }^{3,24}$. The diagnosis of asphyxia during labour was made on abnormal fetal heart rate assessment during labour (on CTG tracing or intermittent doppler), the presence or development of meconium stained liquor during labour and the need for 
resuscitation based on low APGAR scores on delivery or the loss of fetal heart beat which was present during labour (for intrapartum stillbirth). Cord blood gases analysis were not available to provide an objective measure of asphyxia through arterial lactate or $\mathrm{pH}$ on delivery. Other causes of intrapartum stillbirth were related to malpresentation, and obstetric emergencies such as cord prolapse, uterine rupture and placenta abruption. Many of these latter cases were referred from peripheral sites in labour with the loss of fetal heart diagnosed on arrival. Although no formal assessment tool for quality of intrapartum care was used during the reviews, the lack of detection of fetal distress in labour was one of the most commonly recurring themes in intrapartum stillbirths and early neonatal deaths during the monthly perinatal meetings. This may in part be attributed to a lack of awareness by care providers for risk factors for placental insufficiency and a paucity of systematic monitoring for intrapartum asphyxia. Intrapartum stillbirths are frequently used as an indicator of the availability and quality of labour care ${ }^{12}$, and improvement to outcomes will require a robust review of intrapartum care provided.

Prematurity accounted for approximately a third of early NNDs due primarily to the lack of capacity for the provision of invasive ventilation, surfactant and parenteral nutrition. It is likely that sepsis was a contributing and / or causative factor in the cohort of early neonatal deaths but many typical pathogens e.g. GBS and E.coli grown in high income countries are missed because of the lack specialised tests needed to identify them ${ }^{12}$.

The simplified CODAC classification system was developed for use in resource-poor settings where most deaths occur outside hospitals and where there are limitations in investigative capacity. The CODAC system was relatively easy to apply but approximately $45 \%$ of stillbirths in our study were 'unknown', only a slight improvement from $62 \%$ in Wilkins' previous retrospective review $^{6}$. This is in contrast to studies undertaken in other LMIC settings using the CODAC classification system where the proportion of 'unknown' causes ranged from $8 \%$ to $25 \%{ }^{10,25}$. Some of the difficulties in classification in our study were related to: lack of accurate pregnancy dating limiting the detection of both growth-restricted and post-mature fetuses at risk of asphyxia; the lack of documented clinical history and a protocol for systematic examination of stillborn infants; and the limited capacity to confirm suspected diagnoses with investigations. Compounding the latter is the lack of availability for histopathological examination of the placenta and autopsy of the fetus primarily due to cultural taboos.

The strengths of the study stem primarily from the prospective nature of the audit with care undertaken to identify all cases of perinatal mortality presenting to the HNGV maternity unit through regular auditing and intensive collection by the authors during the audit period.

There were a number of limitations in our study. Firstly, many women and their babies are 
discharged relatively early in the post-partum period (within 12 hours) and therefore some early neonatal deaths may not have been captured by the audit. Secondly, data related to birthweight, sex, residence, mode of delivery as well as decision-making to seek care and delay in access to care which may have contributed to the high rate of perinatal loss were not assessed in this study. Future studies into maternal and perinatal outcomes will need to consider some of these factors to allow a focused approach to addressing risk factors contributing to poor perinatal outcomes. Finally, this was a study undertaken at the national referral hospital and may not reflect the situation at the community level in Timor-Leste. Approximately one-half of births in Timor-Leste occur outside a health facility (hospital, CHC or HP) and more than $40 \%$ of all births occur without a skilled provider 5 - therefore an exploration/investigation of the rate of perinatal deaths and possible contributory factors at the community level will be vital in developing policies to mitigate poor perinatal outcomes for the country.

In conclusion, there has been limited improvement in the level of perinatal mortality at HNGV. Improved classification of perinatal deaths through systematic history, examination and investigations is necessary to reduce unknown or un-investigated causes of stillbirth. Additionally, investigation of decision-making to seek care and delay in access to care needs to be undertaken to allow targeted intervention required to improve perinatal outcomes.

\section{Acknowledgements}

The authors would like to acknowledge the contribution of the doctors and midwives of the maternity unit at HNGV in helping with data collection, the Director of HNGV, Dr Jose Guterrus for his support of research activities within the hospital and The Royal Australasian College of Surgeons (RACS) Australia Timor-Leste Program of Assistance for Secondary Services (ATLASS) staff, who provided ongoing support to undertake the study.

\section{$\underline{\text { References: }}$}

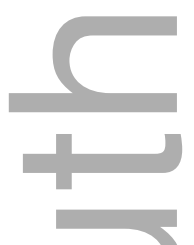

\section{.}

1. Lawn JE, Osrin D, Adler A, Cousens S. Four million neonatal deaths: counting and attribution of cause of death. Paediatric and Perinatal Epidemiology. 2008;22(5):410-6.

2. McClure EM, Saleem S, Pasha O, Goldenberg RL. Stillbirth in developing countries: a review of causes, risk factors and prevention strategies. J Matern Fetal Neonatal Med. 2009;22(3):183-90.

3. Sankar MJ, Natarajan CK, Das RR, et al. When do newborns die? A systematic review of 
timing of overall and cause-specific neonatal deaths in developing countries. Journal of Perinatology. 2016;36 Suppl 1:S1-S11.

4. Travers CP, Carlo WA. How to Save 1 Million Lives in a Year in Low- and Middle-Income Countries. Neonatology. 2017;111(4):431-6.

5. General Directorate of Statistics (GDS) Ministry of Health and ICF. Timor-Leste Demographic and Health Survey 2016. Dili, Timor-Leste and Rockville, Maryland, USA: GDS and ICF.

6. Wilkins A, Earnest J, McCarthy EA, Shub A. A retrospective review of stillbirths at the national hospital in Timor-Leste. Aust N Z J Obstet Gynaecol. 2015;55(4):331-6.

7. Bucens IK, Reid A, Barreto AC, et al. Three years of paediatric morbidity and mortality at the National Hospital in Dili, East Timor. J Paediatr Child Health. 2013;49(12):1004-9.

8. Australian Institute of Health and Welfare 2018. Perinatal deaths in Australia: 2013-2014. Cat. no. PER 94. Canberra: AIHW.

9. United Nations Inter-agency Group for Child Mortality Estimation. Maternal and Newborn Health Disparities - Indonesia. 2015.

10. Flenady V, Wojcieszek AM, Ellwood D, et al. Classification of causes and associated conditions for stillbirths and neonatal deaths. Seminars In Fetal \& Neonatal Medicine. 2017;22(3):176-85.

11. Montagu D, Yamey G, Visconti A, et al. Where do poor women in developing countries give birth? A multi-country analysis of demographic and health survey data. PloS one. 2011;6(2):e17155.

12. Froen JF, Gordijn SJ, Abdel-Aleem H, et al. Making stillbirths count, making numbers talk Issues in data collection for stillbirths. BMC Pregnancy and Childbirth. 2009;9:58.

13. Froen JF, Pinar H, Flenady V, et al. Causes of death and associated conditions (Codac): a utilitarian approach to the classification of perinatal deaths. BMC Pregnancy Childbirth. 2009;9:22. 14. Hospital National Guido Valadares. Department of Obstetrics and Gynaecology Annual Report 2015. Dili, Timor-Leste.

15. World Health Organisation. Neonatal and perinatal mortality : country, regional and global estimates: Geneva : World Health Organization; 2006 [Available from: http://www.who.int/iris/handle/10665/43444.

16. Royal College of Obstetricians and Gynaecologists. Leading Safe Choices - Best practice in postpartum family planning. London, UK; 2015.

17. Jayaratnam S, Soares M, Jennings B, Thapa AP, Woods C. Maternal mortality and 'near miss' morbidity at a tertiary hospital in Timor-Leste. Aust N Z J Obstet Gynaecol. 2019.

18. Ngoc NT, Merialdi M, Abdel-Aleem H, et al. Causes of stillbirth and early neonatal deaths: data from 7993 pregnancies in six developing countries. Bull World Health Organ. 2006;84(9):699- 
705.

19. Di Mario S, Say L, Lincetto O. Riskfactors for stillbirth in developing countries: a systematic review of the literature. Sex Transm Dis. 2007;34:S11-S21.

20. World Health Organisation. Timor-Leste - mortality and burden of disease - Malaria 2016 [Available from: http://www.who.int/malaria/publications/countryprofiles/profile tls_en.pdf?ua=1.

21. Aidsdatahub. Timor-Leste Key facts on HIV Aidsdatahub.org; 2013 [Available from: http://www.aidsdatahub.org/Country-Profiles/Timor-Leste.

22. Flenady V, Froen JF, Pinar H, et al. An evaluation of classification systems for stillbirth. BMC Pregnancy Childbirth. 2009;9:24.

23. Goldenberg R, McCLure EM, Bann CM. The relationship of intrapartum and antepartum stillbirth rates to measures of obsteric care in developed and developing countries. Acta Obstet Gynaecol Scand. 2007;86:1303-9.

24. Lehtonen L, Gimeno A, Parra-Llorca A, Vento M. Early neonatal death: A challenge worldwide. Seminars In Fetal \& Neonatal Medicine.22(3):153-60.

25. Kaistha M, Kumar D, Bhardwaj A. Agreement between international classification of disease (ICD) and cause of death and associated conditions (CODAC) for the ascertainment of cause of stillbirth (SB) in the rural areas of north India. Indian Journal of Public Health.60(1):73-6.

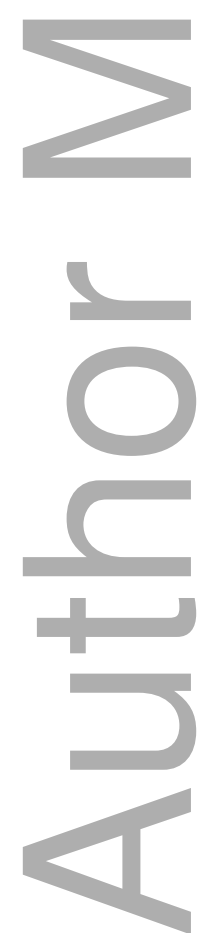

This article is protected by copyright. All rights reserved 


\begin{tabular}{|c|c|c|c|c|c|}
\hline Maternal Age & $\begin{array}{l}\text { Stillbirths } \\
\text { n=110 }(100 \%)\end{array}$ & $\begin{array}{l}\text { Early Neonatal } \\
\text { Deaths } \\
\text { n=28 }(100 \%)\end{array}$ & $\begin{array}{l}\text { Total Perinatal } \\
\text { Deaths } \\
\text { n=138 }(100 \%)\end{array}$ & $\begin{array}{l}\text { Total births } \\
\text { N=2525 (100\%) }\end{array}$ & $\begin{array}{l}\text { Relative Risk of } \\
\text { Perinatal death }\end{array}$ \\
\hline$<20$ & $7(6)$ & $1(3.5)$ & $8(6)$ & $148(6)$ & $1.7(\mathrm{p}=0.179)$ \\
\hline $20-24$ & $20(18)$ & $1(3.5)$ & $21(15)$ & $685(27)$ & 1 \\
\hline $25-29$ & $46(42)$ & $14(50)$ & $60(43.5)$ & $849(34)$ & $2.2(\mathrm{p}=0.0013)^{*}$ \\
\hline $30-34$ & $26(24)$ & $6(22)$ & $32(23)$ & $545(21)$ & $1.9(\mathrm{p}=0.018)^{*}$ \\
\hline $35-39$ & $8(7)$ & $2(7)$ & $10(7)$ & $212(8.5)$ & $1.5(\mathrm{p}=0.27)$ \\
\hline$>=40$ & $3(3)$ & $2(7)$ & $5(4)$ & $73(3)$ & $2.2(\mathrm{p}<0.001)^{*}$ \\
\hline Unknown & 0 & $2(7)$ & $2(1.5)$ & $13(0.5)$ & \\
\hline \multicolumn{6}{|l|}{ Parity } \\
\hline $\mathrm{P} 0$ & $40(36.5)$ & $12(43)$ & $52(38)$ & $1020(41)$ & $1.5(\mathrm{p}=0.258)$ \\
\hline $\mathrm{P} 1$ & $27(24.5)$ & $4(14)$ & $31(22)$ & $592(23)$ & $1.5(\mathrm{p}=0.253)$ \\
\hline $\mathrm{P} 2$ & $9(8)$ & $3(11)$ & $12(9)$ & 341 (14) & 1 \\
\hline P3 & $10(9)$ & $2(7)$ & $12(9)$ & $221(8.7)$ & $1.5(\mathrm{p}=0.277)$ \\
\hline $\mathrm{P} 4$ & $8(7)$ & $2(7)$ & $10(7)$ & $155(6)$ & $1.9(\mathrm{p}=0.166)$ \\
\hline$>=\mathrm{P} 5$ & $15(14)$ & $3(11)$ & $18(13)$ & $187(7)$ & $2.7(\mathrm{p}=0.009) \dagger$ \\
\hline Unknown & $1(1)$ & $2(7)$ & $3(2)$ & $9(0.3)$ & \\
\hline
\end{tabular}

Table 1: Maternal age and parity among women with and without perinatal deaths

Data is presented as $\mathrm{n}(\%)$; *Reference range is $20-24$ year age group; $†$ Reference is P2 
Table 2: Simplified Codac classification (Antepartum stillbirths)

\begin{tabular}{|c|c|c|}
\hline CODAC number & Cause of Death & $\mathbf{n}$ \\
\hline 00 & Chorioamnionitis (unspecified aetiology) & 2 \\
\hline 31 & CNS Congenital anomaly - Anencephaly & 1 \\
\hline 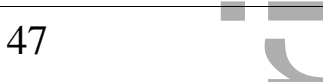 & Hydrops of unknown origin & 1 \\
\hline 51 & True knot in the cord & 1 \\
\hline 63 & $\begin{array}{l}\text { Placental abruption } \\
\begin{array}{l}\text { - } \text { associated pre-eclampsia }\end{array}\end{array}$ & $\begin{array}{l}3 \\
1\end{array}$ \\
\hline 64 & Placental infarction & 1 \\
\hline 71 & Maternal Hypertensive disorder & 17 \\
\hline+5 & $\begin{array}{l}\text { Unknown or un-investigated } \\
\begin{array}{l}\text { - } \\
\text { - } \\
\text { associated IUGR } \\
\end{array}\end{array}$ & $\begin{array}{l}34 \\
5 \\
8\end{array}$ \\
\hline Total Antepartum & Stillbirths & 74 \\
\hline
\end{tabular}


Table 3: Simplified Codac classification (Intrapartum stillbirths)

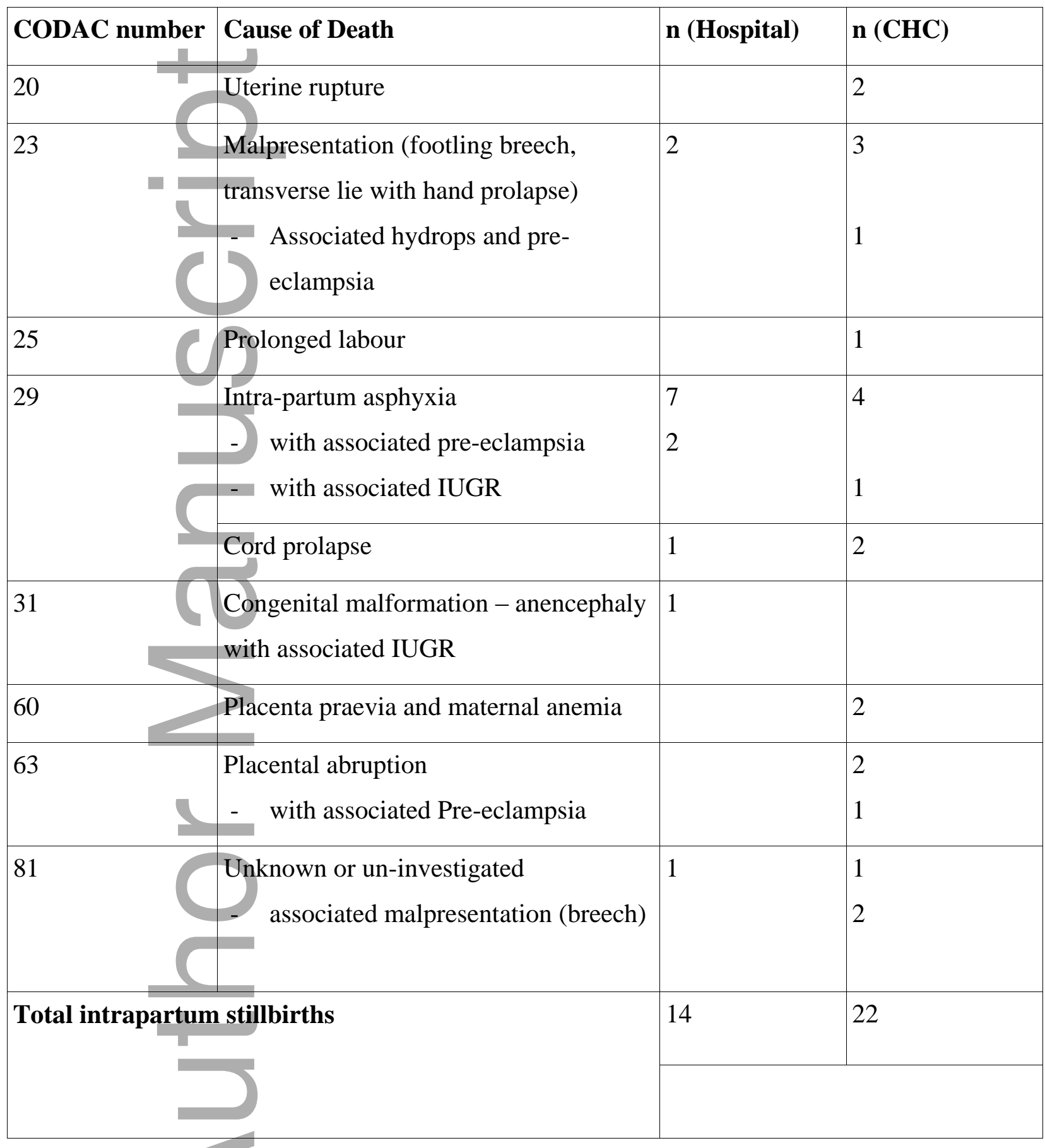


Table 4: Simplified Codac classification (Early neonatal deaths)

\begin{tabular}{|l|l|l|l|}
\hline CODAC number & Cause of Death (Level 1) & Cause of Death (Level 2) & $\mathbf{n}$ \\
\hline 11 & Extreme prematurity & & $9(32 \%)$ \\
\hline 13 & Cardio-Respiratory & Meconium aspiration & $3(11 \%)$ \\
\hline 19 & Infection & Congenital Pneumonia & $1(3.5 \%)$ \\
\hline 29 & Intrapartum & Asphyxia & $14(50 \%)$ \\
\hline 3 & Congenital Abnormality & Skeletal dysplasia & $1(3.5 \%)$ \\
\hline Total (ENND) & & & $\mathbf{2 8}(\mathbf{1 0 0 \%})$ \\
\hline
\end{tabular}

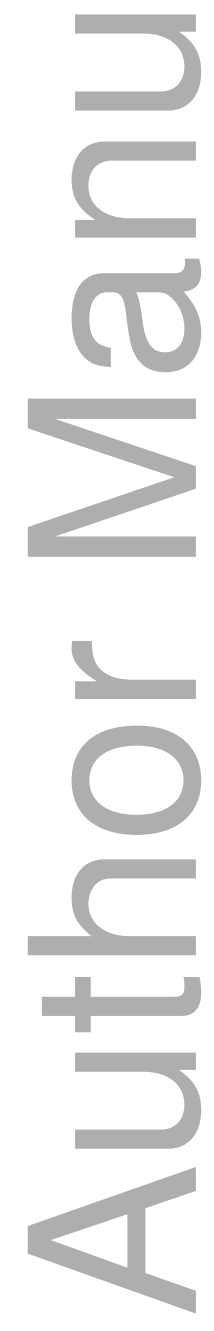




\section{University Library}

\section{- M M N E R VA A gateway to Melbourne's research publications}

Minerva Access is the Institutional Repository of The University of Melbourne

Author/s:

Jayaratnamt, S;Soares, MLDFG;Bucens, I;Jennings, B;Woods, C;Shub, A

Title:

A prospective review of perinatal mortality at Hospital Nacional Guido Valadares (HNGV)

Date:

2020-02-01

Citation:

Jayaratnamt, S., Soares, M. L. D. F. G., Bucens, I., Jennings, B., Woods, C. \& Shub, A. (2020). A prospective review of perinatal mortality at Hospital Nacional Guido Valadares (HNGV). AUSTRALIAN \& NEW ZEALAND JOURNAL OF OBSTETRICS \& GYNAECOLOGY, 60 (1), pp.70-75. https://doi.org/10.1111/ajo.12991.

Persistent Link:

http://hdl.handle.net/11343/285892 